\title{
SIMPLE STEPS FOR SYNTHESIS OF SILICON OXIDE MESOPOROUS MATERIALS USED AS TEMPLATE
}

\author{
J.VELEZ, R.ARCE, D. ALBURQUENQUE, J.L. GAUTIER, C. ZUNIIGA AND F. HERRERA* \\ Department of materials Chemistry, Institution Universidad de santiago de Chile, Address Av. Libertador B. O'Higgins 3360, \\ Estación Central Santiago de Chile.
}

(Received: June 28, 2013 - Accepted: September 24, 2013)

\begin{abstract}
A novel methodology for the synthesis of silicon oxide mesoporous materials has been developed using soft reaction conditions, unlike other synthesis conditions present in the literature. The synthesis involves the use of the lyotropic liquid crystals formed by mixing the surfactant hexadecyltrimethylazanium (CTAB), sodium nitrate as catalyst, water and tetraethyl orthosilicate (TEOS) as the inorganic precursor. The silicon oxide samples were characterized by high-resolution transmission electron microscopy (HRTEM) and EDX analysis. The specific surface area of the powder and the pore size were determined by the BET method and were found to be $587 \mathrm{~m}^{2} / \mathrm{g}$ and 2-4 nm, respectively. The point of zero charge (pzc) determination using a zeta-meter apparatus was 3.1 showing the acid character of the surface. The template mesoporous $\mathrm{SiO}_{2}$ samples can be used to prepare composite electrodes containing active mixed oxides, e.g. for lithium-ion batteries.
\end{abstract}

\section{INTRODUCTION}

The synthesis of new nanostructured materials is a field in constant development because at that size scale the physicochemical properties of matter change significantly. Indeed, different nanostructures have been synthesized, including nanowires, nanotubes and nanopores. There are different synthesis methods to prepare these nanomaterials, the most common being the chemical vapour deposition (CVD), thermal decomposition of precursors, co-precipitation, sol-gel, microwave, electrochemical methods, and chemical solvo-thermal synthesis ${ }^{1-7}$. It is well known that the synthesis of nanostructures is possible using templates. Different supramolecular structures, e.g. lamellar, hexagonal, and cubic or smectic mesophases, can be used as templates. They can be obtained on the basis of surfactant/water or polymer/water mixtures ${ }^{8}$. Lin et al. have functionalized these compounds, which allowed the design of nanometric scale containers that can be used as carriers for molecules of biological interest, such as therapeutic proteins, enzymes and polynucleotides ${ }^{10,11}$. In the battery field, $\mathrm{Wu}$ et al. ${ }^{12}$ have prepared mesoporous of titanium using templates as anodes for lithium-ion batteries, improving their charge-discharge cycle characteristics. More recently, Wang et al. ${ }^{6}$ have developed three methods for the synthesis of mesoporous $\mathrm{SiO}_{2}$ hollow spheres with uniform pore diameter of $3.6 \mathrm{~nm}$ to $3.8 \mathrm{~nm}$. These hollow spheres allow the encapsulation of different types of metals ( $\mathrm{Au}, \mathrm{Ag})$, semiconductors $\left(\mathrm{ZnS}, \mathrm{TiO}_{2}, \mathrm{Co}_{3} \mathrm{O}_{4}, \mathrm{Fe}_{2} \mathrm{O}_{3}{ }^{17}\right)$ and conductive polymers (polyaniline)

In general, the route to obtain mesoporous materials involves the use of supramolecular structures (templates) and a strong acid medium, high temperatures and pressures. These parameters directly influence the properties of the obtained mesoporous templates, such as type of structure, morphology, specific surface area, pore size and thickness of the wall. Additionally, other factors has been considered: the surfactant concentration, the surfactant/inorganic precursor ratio and the acidity of the medium. Xiao et al. ${ }^{13}$ studied the effect of the temperature on the synthesis of mesoporous silica nanofibers obtained at 283 $\mathrm{K}$ exhibiting a specific surface area of $952 \mathrm{~m}^{2} / \mathrm{g}$. As the temperature increased from $283 \mathrm{~K}$ to $293 \mathrm{~K}$ and to $308 \mathrm{~K}$, the specific surface areas of the mesostructure containing aggregates of particles, decreased to $656 \mathrm{~m}^{2} / \mathrm{g}$ and $462 \mathrm{~m}^{2} / \mathrm{g}$ respectively.

J.H. Zhu et al. ${ }^{14}$ studied the effect of the molar TEOS/HNO ratio on the ordering degree of the mesophase obtained. These authors have found out that when the molar ratio TEOS/ $\mathrm{HNO}_{3}$ exceeds 3.5 , the mesophase loses its structural order. Another conclusion of this work is related to the absence or presence of phenol in the mixture. It was determined that when the $\mathrm{CPyCl}$ to phenol molar ratio is $1: 1$, the generated mesophase is cubic, while in the absence of phenol a hexagonal shape is obtained. Meanwhile, when the ratio is 1:2, lamellar silica is obtained.

In this work, we present a methodology for the synthesis of silicon oxide mesoporous materials under soft reaction conditions, namely one atmosphere, $313 \mathrm{~K}$ and $\mathrm{pH}=7$. The synthesis involves the use of a lyotropic liquid crystal as the template, as suggested by Xiao et al. ${ }^{13}$

\section{EXPERIMENTAL}

The mesoporous silicon oxide was prepared by steps using the following molar ratios $0.35 \mathrm{CTAB} / 0.053 \mathrm{NaNO}_{3} / 1$ TEOS/ $10 \mathrm{H}_{2} \mathrm{O}$. The first step was the preparation of the liquid crystals, whereby a mixture containing $7.5 \mathrm{~g}$ of $\mathrm{CTAB}$ and $0.26 \mathrm{~g}$ of $\mathrm{NaNO}_{3}$ in $10.2 \mathrm{~g}$ of $\mathrm{H}_{2} \mathrm{O}$ was used. To ensure total dissolution of the solids, the mixture was stirred and heated to $368 \mathrm{~K}$. Once the mixture reached room temperature (RT), the mixture was stabilized for one day at $313 \mathrm{~K}$ in a thermal regulated bath. After some time, the mixture changed to a transparent liquid phase. At this point, $1.17 \mathrm{~g}$ of TEOS was added and then the new mixture was allowed to react at $313 \mathrm{~K}$ for 4 days. The final solution changed from transparent to a white gel, in which the mesoporous materials (hard template) and the liquid crystal (soft template) coexists. To eliminate the soft template, the product was washed up several times with distilled water and then heated to $343 \mathrm{~K}$ until a solid white powder was obtained. The excess of surfactant inside the pores was eliminated by calcination. The experimental conditions for this heating process involved going from RT to $573 \mathrm{~K}$ at a heating rate of $2.5^{\circ} \mathrm{C} / \mathrm{min}$. Once this last temperature was obtained, it was maintained for 1.5 hours. After that, the temperature was raised again to $813 \mathrm{~K}$ at a $1.5^{\circ} \mathrm{C} / \mathrm{min}$ heating rate, which was maintained for 6 hours. When the oxidation process was finished, the obtained material (mesoporous silicon oxide) was washed several times with deionized water to eliminate the excess of ions. All analyses were performed on the calcined samples.

Nanostructured Characterization

The EDX and Microscopy analyses were carried out using a high resolution EDAX transmission electron microscope (HRTEM), by FEI, Tecnai G2 F20 S-Twin model, equipped with a spectroscopy system and X-ray microanalysis. The surface area and pore diameter were also determined by the BET method, using a Micromeritics apparatus, model ASAP 2020. The BET method gives pore results with a precision better than the HRTEM method. The isotherms obtained from BET measurements were carried out in the range of pressure from 0 to $1 \mathrm{~atm}$

\section{Surface Characterization}

The acidity and basicity of sites or groups on the bare surface were estimated by pzc determinations using a zeta-meter 3.0 apparatus. Similarly, to differentiate between charged and uncharged surfaces, the $\mathrm{pHz}$ was determined using a simple acid-base titration, with a standard solution containing $30 \mathrm{mg}$ of sample, $300 \mathrm{ml} \mathrm{H}_{2} \mathrm{O}$ and $0.1 \mathrm{M} \mathrm{KCl}^{15}$.

\section{RESULTS AND DISCUSSION}

To control the powder formed which should correspond to mesoporous $\mathrm{SiO}_{2}$, two types of analyses were carried out: The first analysis was to characterize the morphology using HRTEM (fig.1). In this figure, we can see that the spherical nanoparticles are formed by a semi-disordered fibrous framework, possibly $\mathrm{SiO}_{2}$, leading to the generation of porous cavities between the fibers. To determine if the fibers are actually formed by $\mathrm{SiO}_{2}$ was necessary to carry out EDX analysis. Figure 2 shows the result of EDX coupled to a STEMHADDF. As is clear from the EDX analysis, the synthesized material is made 
only silicon and oxygen.

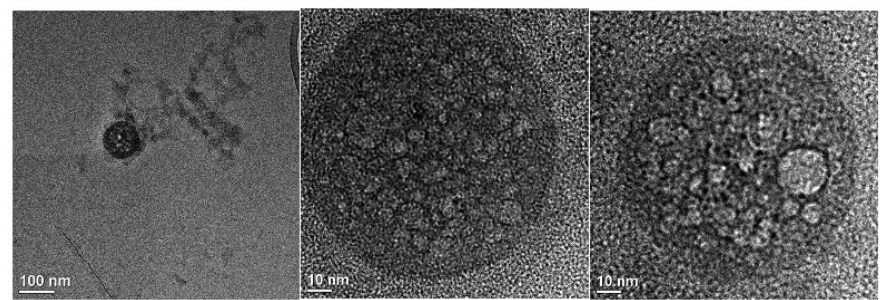

Figure 1. HRTEM images series for the sample $\mathrm{m}-\mathrm{SiO}_{2}$.
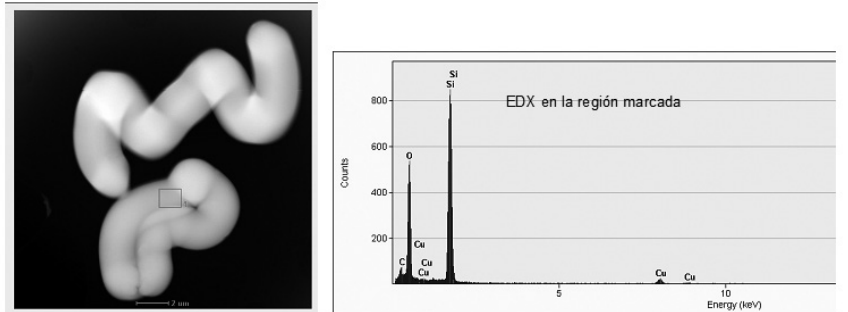

STEM - HAADF (high angle annular dark field) $300 \mathrm{kV}$

Figure 2. STEM-HAADF and EDX measurements for the sample synthesized under conditions previously mentioned

BET measurements are used primarily to determine the pore diameter with surface area. Moreover, this measure allows us to obtain a classification of the pore size, since the shape of the adsorption isotherm allows to catalog the compound obtained as micro-, meso or macroporous. Figures 3A and 3B show the curves obtained by BET measurement, allowing to obtain the above parameters. Figure $3 \mathrm{~A}$ shows the pore diameter distribution as a function of pore volume, as can be appreciated the majority pore diameter is in the range of $2 \mathrm{~nm}$ to $4 \mathrm{~nm}$. On the other hand, Fig. 3B shows a typical IV adsorption isotherm type characteristic of mesoporous solids, with a hysteresis loop associated with tubular capillaries open at both ends. From this isotherm it was possible to obtain the surface area of $\mathrm{SiO}_{2}$, whose calculated value was 587 $\mathrm{m}^{2} / \mathrm{g}$. This relatively high value indicates a high density of pores available for using $\mathrm{SiO}_{2}$ as template. From these results it is possible to confirm the formation of mesoporous structures.
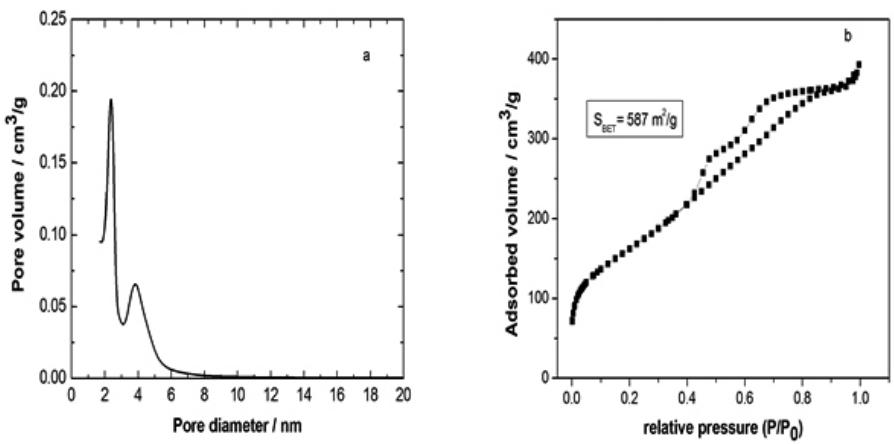

Figure 3. BET analysis of mesoporous silicon oxide. A) Pore volume vs. pore diameter, B) volume of gas adsorved vs relative pressure.

Furthermore, to characterize the charge on the surface of the mesoporous silicon oxide, we determined the isoelectric point as a function of $\mathrm{pH}$. Figure 4 shows the results for two measurements. In both cases the intercept of these curves with the $\mathrm{pH}$ axis present the same value for the point of zero charge, $\mathrm{pzc}$, at $\mathrm{pH} 3.1$ indicating that their surface is positively charged. This parameter is important to expand the scope of the use of silicon oxide as the template, to manufacture, for example, mixed oxide electrodes for lithium-ion batteries, since most of the oxides used in the manufacture of these devices are formed from negatively charged precursors. Therefore, positively charged surfaces favor the encapsulation of these precursors within the template.

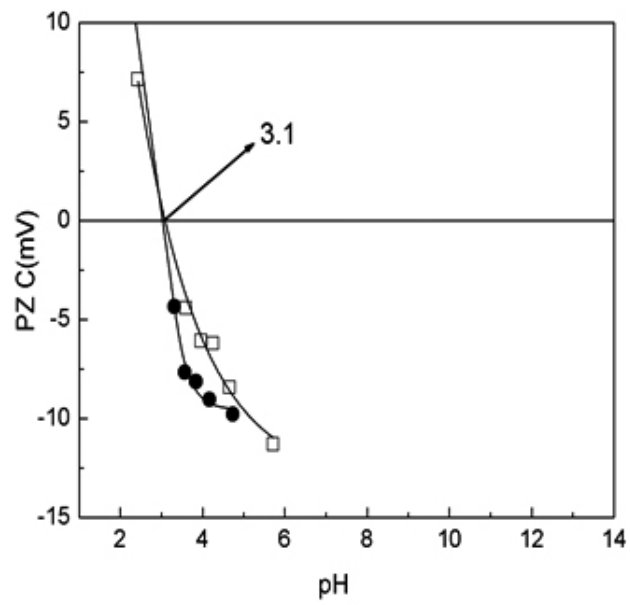

Figure 4: Point of zero charge vs. pH for mesoporous silica. Symbols and represent two measures for a same sample.

To the previously stabilized liquid crystal solution, the inorganic precursor is added, and the system is allowed to react for 24 hours. The calcination of the material takes place under conditions of controlled temperature, as described above, because the nanostructure collapses under more severe conditions.

According to Xiao et al. ${ }^{13}$, the concentration of the $\mathrm{NO}_{3}$ - ions plays an important role on the catalytic hydrolysis of TEOS and the formation of the final nanostructure. In fact, depending on the $\mathrm{NaNO}_{3} / \mathrm{TEOS}$ molar ratio used, the particle morphology that is obtained changes from aggregate particles $\left(\mathrm{NaNO}_{3} /\right.$ TEOS $=0.3)$ to fiber $\left(\mathrm{NaNO}_{3} / \mathrm{TEOS}=1\right)$. The role of the $\mathrm{NO}_{3}{ }^{-}$can be explained on the basis of the $\mathrm{NO}_{3}^{-}$anion having a high binding selectivity in relation to the cationic surfactant ${ }^{3} \mathrm{CTA}^{+}$and leading to long cylindrical micelles which would facilitate the formation of the nanostructure ${ }^{16}$. Currently, we are conducting work to clarify this further.

\section{CONCLUSIONS}

Silicon oxide mesoporous materials can be easily prepared using a soft template route which involves the initial formation of the liquid crystal with CTAB in water using $\mathrm{NaNO}_{3}$ as the catalyst, followed by the addition of TEOS at $\mathrm{pH}=7$, one atmosphere and $313 \mathrm{~K}$. This technique appears as very convenient when compared with others, which are used under very extreme experimental conditions of acidity, temperature and pressure. The mesoporous silicon oxide thus synthesized shows a low distribution of pore sizes, between 2 to $4 \mathrm{~nm}$. Such mesoporous material can be used as a template in the manufacture of battery electrodes, sensors, optoelectronic devices and catalysts.

\section{ACKNOWLEDGEMENT}

The authors thank the financial support of CONICYT-USACH project $\mathrm{N}^{\circ}$ 79090024. JLG thanks Fondecyt project 1110755.

\section{REFERENCES}

1. H. Yoshitake, T. Sugihara, T. Tatsumi, Chem. Mater. 14, 1023, (2002)

2. W. Li, H. Zhang, C. Wang, Y. Zhang, L. Xu, K. Zhu, S. Xie Appl. Phys. Lett., 70, 2684, (1997).

3. L. Wang, Z. Wang, J. Zhao, Z. Yuan, H. Yang, M. Zhao, Mater. Chem. Phys., 59, 171, (1999).

4. M. Fantinia, J.R. Matosb, L.C. C. da Silvab, L.P. Mercuric, G.O. Chierecic, E.B. Celerd, M. Jaroniec, Mater. Sci. Eng., B, 112, 106, (2004).

5. Z. Gana, G. Ninga, Y. Lina, Y. Congc Mater. Lett. 61, 3758, (2007).

6. D.P. Wang, H.C.Zeng, Chem. Mater. 23, 4886, (2011).

7. H. Liu, M. Wang, H.Hu, Y.Liang, Y.Wang, W.Cao and, X. Wang, J. Solid State Chem., 184, 509, (2011)

8. M. Tiemann, Chem. Mater., 20, 961, (2008).

9. M. Lin, C. Huang, M. Lo, C. Mou, J. Phys. Chem. C 112, 867, (2008).

10. G. Surendran, L. Ramos, B. Pansu, E. Prouzet, P. Beaunier, F. Audonnet, H. Remita, Chem. Mater.,19, 5045, (2007). 
11. B. Trewyn, I. Slowing, S. Giri, H. Chen, V. Lin, Acc. Chem. Res.,40, 846, (2007).

12. L.J. Fu, T. Zhang, Q. Cao, H.P. Zhang, Y.P. Wu, Electrochem. Commun., 9, 2140, (2007)

13. Q. Xiao, J.Wang, H.Zhou, P. Sun, Z. Yuan, B. Li, D. Ding, T.Chen, Microporous Mesoporous Mater., 109, 233, (2008).
14. J. Zhu, H. Wang, Z. Wu, Y. Wang, Mater. Lett., 62, 422, (2008).

15. J.L.Gautier, A.Restovic, G.Poillerat, P.Chartier, Eur.J. Solid State and Inorg. Chem., 34, 367, (1997).

16. H.P. Lin, C.P. Kao, C.Y. Mou, S.B. Liu, J. Phys. Chem. B, 104, 7885, (2000).

17. C. Han, J. Xie, C. Deng. D. Zhao, J. Chil.Chem. Soc, 57, 4, (2012) 